\title{
Methodology for assessing electric vehicle charging infrastructure business models
}

\author{
Carlos Madina ${ }^{\mathrm{a}, *}$, Inmaculada Zamora ${ }^{\mathrm{b}}$, Eduardo Zabala ${ }^{\mathrm{a}}$ \\ a Tecnalia Research E Innovation, Parque Tecnológico de Bizkaia, c/Geldo, Edificio 700, 48160 Derio, Spain \\ ${ }^{\mathrm{b}}$ Department of Electrical Engineering, University of the Basque Country (UPV/EHU), Alameda Urquijo s/n, 48013 Bilbao, Spain
}

\section{H I G H L I G H T S}

- Ecosystem is a network of actors who collaborate to create a positive business case.

- Electro-mobility (electricity-powered road vehicles and ICT) is a complex ecosystem.

- Methodological analysis to ensure that all actors benefit from electro-mobility.

- Economic analysis of charging infrastructure deployment linked to its usage.

- Comparison of EV ownership cost vs. ICE for vehicle users.

\section{A R T I C L E I N F O}

\section{Article history:}

Received 24 June 2015

Received in revised form

24 November 2015

Accepted 7 December 2015

\section{Keywords:}

Electric vehicles

business models

charging infrastructure

\begin{abstract}
A B S T R A C T
The analysis of economic implications of innovative business models in networked environments, as electromobility is, requires a global approach to ensure that all the involved actors obtain a benefit. Although electric vehicles (EVs) provide benefits for the society as a whole, there are a number of hurdles for their widespread adoption, mainly the high investment cost for the EV and for the infrastructure. Therefore, a sound business model must be built up for charging service operators, which allows them to recover their costs while, at the same time, offer EV users a charging price which makes electro-mobility comparable to internal combustion engine vehicles. For that purpose, three scenarios are defined, which present different EV charging alternatives, in terms of charging power and charging station ownership and accessibility. A case study is presented for each scenario and the required charging station usage to have a profitable business model is calculated. We demonstrate that private home charging is likely to be the preferred option for EV users who can charge at home, as it offers a lower total cost of ownership under certain conditions, even today. On the contrary, finding a profitable business case for fast charging requires more intensive infrastructure usage.
\end{abstract}

(c) 2015 Elsevier Ltd. All rights reserved.

\section{Introduction}

A business ecosystem is an economic community supported by interacting organisations (including suppliers, producers, competitors and other stakeholders), which produces goods and services of value to customers, who are themselves members of the

\footnotetext{
Abbreviations: A, ampere; AC, alternating current; B2B, business-to-business; $\mathrm{B} 2 \mathrm{C}$, business-to-customer; $\mathrm{CO}_{2}$, carbon dioxide; $\mathrm{CS}$, charging station; $\mathrm{CSO}$, charging service operator; DC, direct current; DSO, distribution system operator; EMSP, electro-mobility service provider; EU, European Union; EV, electric vehicle; ICE, internal combustion engine; IEC, International Electrotechnical Commission; l, litre; km, kilometre; kW, kilowatts; kWh, kilowatt-hour; O\&M, operation and maintenance; RFID, radio-frequency identification; TCO, total cost of ownership; VAT, value-added tax

* Corresponding author.

E-mail address: carlos.madina@tecnalia.com (C. Madina).
}

ecosystem. The capabilities and roles and organisations evolve over time, but all of them have a shared vision to align their investments and to find mutually supportive roles (Moore, 1996). The term refers to "communities of economic actors whose individual business activities share in some large measure the fate of the whole community" (Moore, 2006, p. 33). This means that all actors can benefit from the existence of the ecosystem, but also that they need to contribute to it. Electro-mobility (the use of electricity for powering the drive trains of road vehicles ${ }^{1}$ ) falls within this definition, because it is a complex system where

\footnotetext{
${ }^{1}$ Due to the very diverse technologies and actors/roles needed to allow the change of paradigm in transport, electro-mobility cannot be understood without massive information and communication technology (ICT), in order to monitor both the state of the battery and the charging process, to manage and transmit all the data monitored and to inform EV users about different value-added services (charging station location and reservation, eco-routing, etc.).
} 
multiple actors interrelate with each other and must collaborate to make electro-mobility feasible. The economic and regulatory implications of this kind of complex environments have been analysed for different fields of the energy sector, in particular regarding energy efficiency programmes (Abrardi and Cambini, 2015; Eto et al., 1998; Hannon et al., 2013).

Although the adoption of electric vehicles (EVs) provides clear benefits for the society as a whole in terms of efficiency and environmental impact (Bohnsack et al., 2014; Gomez et al., 2011), it requires profound changes in the technologies to be used and in the roles to be performed by the different actors in the valuechain, which result in a number of barriers for its adoption. From the EV user perspective, main barriers include long charging times, shorter driving range and, especially, higher initial investment, even if running costs are lower for EVs when compared to internal combustion engine (ICE) vehicles. Moreover, the limited availability of charging stations (CS) for electric vehicles, which results from the high investment costs for their developer and the uncertainty about their use, is an additional barrier for EV users who cannot charge their EVs at home (Kley et al., 2011; Markkula et al., 2013; Wiederer and Philip, 2010).

Therefore, a sound business model must be built up for the charging service operator (CSO), so that it develops the required CS infrastructure while, at the same time, EV user experience must be improved, in order to overcome the barriers discussed above (Gomez et al., 2011; Kley et al., 2011; Markkula et al., 2013; Schroeder and Traber, 2012).

In general, a business model is a representation of how an organisation creates value for its customers and how that value is then shared between the organisation and the customers (Osterwalder and Pigneur, 2010; Magretta, 2002).

When dealing with business models related to electro-mobility, the whole ecosystem must be considered due to the complex interactions between stakeholders, many of which were not part of the value chain of neither ICE vehicles nor electricity supply (Kley et al., 2011). There are studies that focused on the business model for the car manufacturer (Bohnsack et al., 2014; Kley et al., 2011) or for the infrastructure developer (Markkula et al., 2013; Schroeder and Traber, 2012). However, an integrated view over the different stakeholders is still needed, which can be used for policy makers and regulatory bodies to design the policy and regulatory framework to better promote electro-mobility (Gomez et al., 2011; Kley et al., 2011).

According to Eto et al. (1998, p. 2), "the overriding regulatory objective is the maximisation of social value or societal net benefits". This means that the regulator aims at maximising the benefits for a set of involved stakeholders, while reducing their overall costs. If the regulator has perfect information about stakeholders' costs and benefits, the task of regulation design becomes easy, but this is not common in existing markets (Eto et al., 1998; Stoft and Gilbert, 1994) and even less in brand new environments as electro-mobility is. Moreover, regulation should promote a right allocation of benefits and efforts between the different stakeholders, which makes this task even more difficult, especially if the protection of vulnerable customers is also included as an additional goal for the regulator (Abrardi and Cambini, 2015).

In this context, this paper presents the results of an integrated assessment of the economic feasibility for different EV charging infrastructure options to help regulatory authorities best design the infrastructure deployment strategy. It is not the aim of this paper to provide exact results, but rather to provide an estimation of the potential for different charging alternatives, based on robust data sources and assumptions. ${ }^{2}$ The study presented here

\footnotetext{
${ }^{2}$ This paper is based on the economic assessment performed in the EU FP7 project Green eMotion (http://www.greenemotion-project.eu/ (last access in June
}

considers average values for different parameters, instead of taking into account the very diverse potential alternatives that may happen. ${ }^{3}$ This approach makes the analysis more straightforward and permits analysing different charging alternatives. Although it reduces the accuracy of the study, the future of electro-mobility is difficult to predict and the assumptions considered are expected to be good enough to identify future trends in CSO business performance.

Section 2 presents the roles of the actors in the electro-mobility ecosystem and defines the scenarios to be considered. Section 3 describes the methodology proposed and assesses the main cost components for the main actors. Section 4 shows the different case studies and discusses their main results. Section 5 summarises the main conclusions of the analysis.

\section{Roles and scenarios}

The ecosystem can only be sustainable in the long-term when every stakeholder obtains a positive business case, or a valuable good or service in the case of EV users. Stakeholders may be new entrants that want to create a new business, regulated companies, actors playing in competitive environments or end customers (EV users).

Due to the different regulatory options already envisaged (what Eurelectric (2010), Eurelectric (2013) call "market models"), the analysis presented here focuses on roles rather than on stakeholders. The new roles can be performed by new entrants or by established actors, but the duties and responsibilities will be defined by the role. Different regulatory options will result in one or more roles being performed by the same stakeholder, but they should not affect their profitability in competitive markets (Schroeder and Traber, 2012).

The electro-mobility service provider (EMSP) is one of the key new roles needed in the EV-ecosystem. It offers electro-mobility services to the end customers, which may include charging, search \& find, routing and other services. It is the legal entity that the end-customer has a contract (business-to-customer (B2C) relationship) with for all services related to the EV. This provision of services, including the EV charging services (either at home, at work or at any other location), is the feature that characterises the EMSP. The EMSP is owner of the data of the EV users in its portfolio.

The CSO has the role of operating the physical equipment to supply the charging process of the EV. Moreover, it is responsible for the management of the charging session, as well as for monitoring, maintaining and controlling a certain CS. The CSO offers charging services (access to charging infrastructure, including energy) to the EMSP based on a business-to-business (B2B) relationship, either directly or through an agreement with a third party (e.g. a marketplace operator). It is the owner of all the data related to the CS.

A third new role is the Marketplace Operator. The marketplace is a virtual B2B environment (no end customers are allowed) for services related to electro-mobility, accessible through the internet and hosted in a cloud environment. Any business partner can

\footnotetext{
(footnote continued)

2015)), whose outcome is summarised in Madina et al. (2015). Leading equipment manufacturers, electric utilities and car manufacturers contributed to several workshops where the data and assumptions were agreed, based on the best data available during the project execution phase.

${ }^{3}$ For example, each charging session will demand a different amount of energy, because not all the EVs will reach the CS with the same battery state of charge and not all of them will need to top up the battery; each EV user will have a driving behaviour and each trip will follow a different route, leading to different EV efficiencies; and there are different EV models available, in terms of size, weight, battery capacity, efficiency, etc.
} 


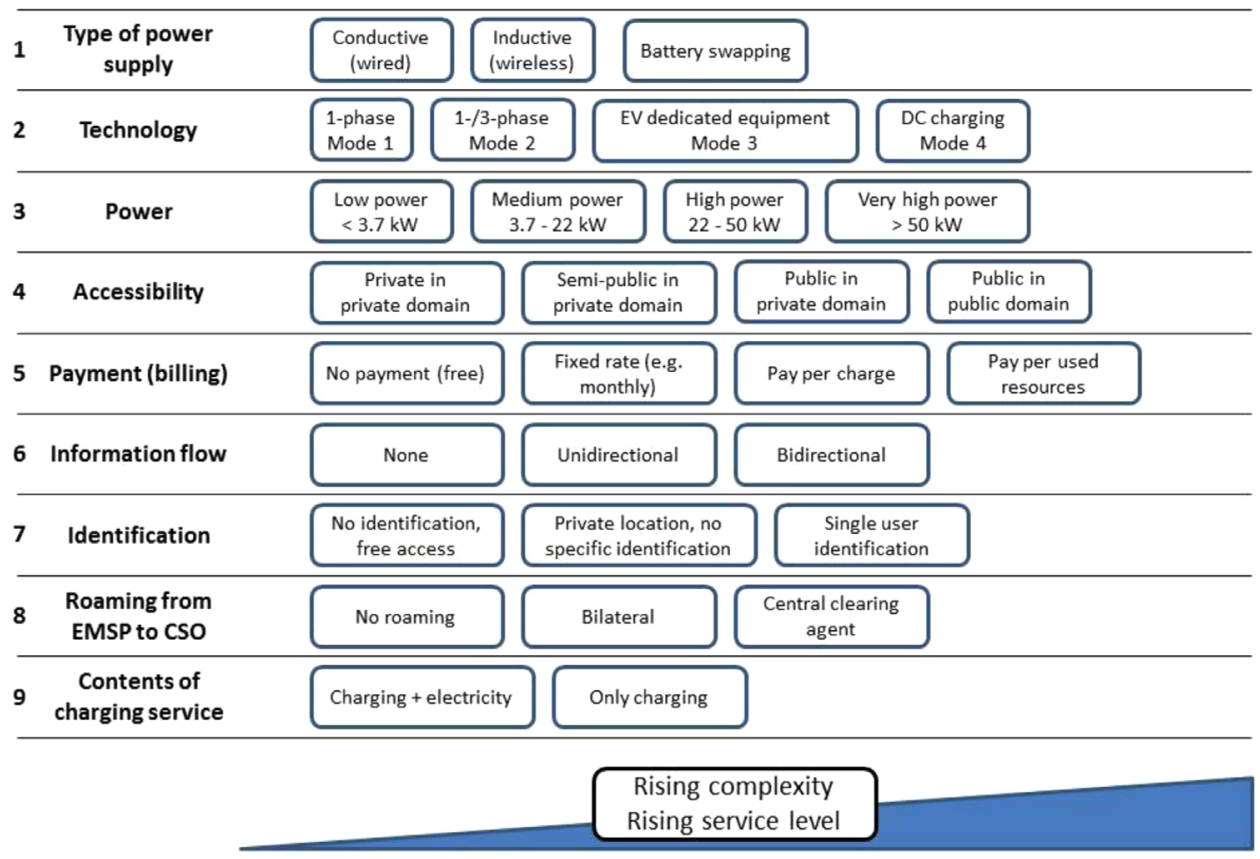

Fig. 1. Morphological box for the different charging alternatives for EVs.

offer its EV services on the marketplace, which can then be bought by any other business partner. EV services include authentication and authorisation, EV charging, CS reservation, routing..., as well as clearing services. Clearing allows CSOs to ask for validation of EV users (contract clearing) and to forward the Charge Detail Record so that the corresponding EMSP pays for the charging session (financial clearing).

In addition to the new roles, another important feature of electro-mobility is that there are many aspects of a charging event which have several options. By using the morphological box analysis (Kley et al., 2011; Markkula et al., 2013), Fig. 1 presents the different alternatives to be considered when dealing with EV charging.

Based on Fig. 1, several tens of thousands of potential alternatives can be envisaged for EV charging, which gives an idea of the complexity of electro-mobility field. Since not all the feasible choices could be presented in this analysis, the most relevant ones have been considered to define three likely scenarios for EV charging. The scenarios are created by considering that some parameters in Fig. 1 are constant, while some others are different in each scenario. Regarding constant parameters, conductive charging (row 1), payment per used resources (row 5), bidirectional information flow (row 6) and the charging service including electricity $^{4}$ (row 9 ) are taken into account. In addition, only Mode 3 is considered for AC charging and Mode 4 for DC charging (row 2 ), and single-user identification applies to all cases, except for private charging (row 7). As a result, different options have been analysed for charging power (row 3), accessibility (row 4) and roaming (row 8), leading to the three scenarios described below:

1. Traffic hotspot charging: publicly accessible CS on private property and medium power AC charging ( $22 \mathrm{~kW})$. There is no roaming, as the hotspot operator is performing the roles of both the EMSP and the CSO.

2. Highway charging: publicly accessible CS on private property and high power DC charging (50 kW). There is roaming through a central clearing actor (the Marketplace Operator).

\footnotetext{
4 "Roaming of charging service" as defined in Eurelectric (2013).
}

3. Private home charging: Private CS in restricted-access private property $^{5}$ and low power AC charging $(3.7 \mathrm{~kW})$. No roaming is required, as the CSO is the $\mathrm{EV}$ user.

\section{Methodology proposed}

In order to assess the potential for the different scenarios described, the proposed methodology considers that any successful business model must create value for final users, while at the same time, allow the different stakeholders to recover their costs and make a profit.

When there is enough competition in the market, together with a minimum level of standardisation, market actors cannot make use of market power (Schroeder and Traber, 2012) and, hence, their profit will stem from providing value to EV users, rather than from rent extraction.

The methodology is the same for all the scenarios. First, the value chain is identified. Then, the costs for each of the new roles are calculated and their required incomes are calculated in order to cover costs. Last, the resulting costs for EV users are calculated and compared against the costs of using ICE vehicles. As far as EV costs are lower, a competitive business model can be found (Markkula et al., 2013; Schroeder and Traber, 2012).

\subsection{Conditions for building up a profitable business model}

In order to be profitable, any business model needs to (1) create value for customers and (2) provide economic profits for the companies creating the value.

Value for customers can be created by providing valuable goods and services or by ensuring economic savings with respect to alternative options (with a comparable service level), i.e. when a new service is provided or when an "old" service is provided either in a more convenient way or at a lower cost. In the case of electromobility, there are a number of advantages in terms of user

\footnotetext{
${ }^{5}$ Such as the garage at home or the depot of a fleet, where only those vehicles with the required access rights can use the parking space.
} 
experience with respect to ICE vehicles, including faster acceleration, higher efficiency and lower operational costs, but higher investment cost is still one of the main barriers for EV adoption (Bohnsack et al., 2014; Gomez et al., 2011; Kley et al., 2011; Markkula et al., 2013; Wiederer and Philip, 2010). Therefore, any successful EV business model should keep the perceived preference for EVs over ICE vehicles, while having a similar or lower cost for EV users. ${ }^{6}$

The second condition is met when the stakeholders performing the new roles in the market (EMSP, DSO, Marketplace Operator...) can obtain incomes which exceed their costs. However, these roles are closely interrelated, i.e. the prices requested by the Marketplace Operator become costs for EMSPs and/or CSOs, and the prices requested by CSOs can also increase the costs for EMSPs.

The marketplace is a complex ICT environment where both the contractual and the financial clearing are performed. Innovative business models like this have two main aspects that may affect the success of its business model. On the one hand, there is the risk associated with being the first company to experiment a new business model (Hannon et al., 2013), including the risk of becoming obsolete, if a better solution, resulting from technological development, appears as a competitor in the market (Wiederer and Philip, 2010). On the other hand, they also have the advantage of being able to gain competitive advantage (Bohnsack et al., 2014) and become the de facto standard if they gain rapid market share and provide a convenient solution for business partners. The first marketplaces for trading services related to electro-mobility are starting their commercial operation in recent years (Hubject, e-clearing.net). Although the growth of electro-mobility is not as fast as expected, ${ }^{7}$ they have been able to create a good partner base. $^{8}$ Therefore, their pricing strategies can be used as a benchmark for this analysis, because they are expected to be designed to make them economically profitable and they seem to be attractive enough for their target customers (EMSPs and CSOs).

\subsection{Main cost components}

\subsubsection{Charging Service Operator (CSO)}

In the most general case, the costs for the CSO are those related to the charging infrastructure, electricity bill costs, communication costs, costs for accessing the marketplace $\left(\mathrm{CSO}_{\mathrm{MP}}\right)$ and staff and overhead costs, as shown in Eq. (1).

$$
\begin{aligned}
\mathrm{CSO} \text { cost }= & \mathrm{CSO}_{\text {Infrastructure }}+\mathrm{CSO}_{\text {Electricity bill }}+\mathrm{CSO}_{\text {Communications }} \\
& +\mathrm{CSO}_{\mathrm{MP}}+\mathrm{CSO}_{\text {Staff \& Overheads }}
\end{aligned}
$$

The costs related to infrastructure include the operation and maintenance $(\mathrm{O} \& \mathrm{M})$ costs related to each $\mathrm{CS}\left(C S_{O \& M}\right)$, as well as the annual amortisation of CS investment. Taking average values, total infrastructure costs depend on the total number of CS $\left(N_{C S}\right)$ and can be calculated according to Eq. (2).

$$
\mathrm{CSO}_{\text {Infrastructure }}=\left(C S_{\text {Amortisation }}+C S_{O \& M}\right)^{*} N_{C S}
$$

Annual amortisation is calculated in Eq. (3) by using the annuity factor as defined e.g. in Schroeder and Traber (2012), which considers the CS investment cost $\left(C S_{I}\right)$, the discount rate $\left(C S_{d}\right)$ and the CS lifetime $\left(C S_{y}\right)$.

\footnotetext{
${ }^{6}$ Although this is the common sense condition, customers not always take rational decisions, even if they have all the information they need (Abrardi and Cambini, 2015), especially when buying a car (Kley et al., 2011).

${ }^{7}$ Updated information about mobility plans and achievement in different EU Member States can be found at: http://ev-observatory.eu/category/resources/coun tries/ (last access in June 2015).

${ }^{8}$ See for example http://www.hubject.com/pdf/PM_hubject_20150324_EN.pdf (last access in June 2015).
}

$\mathrm{CSO}_{\text {Amortisation }}=\frac{C S_{I}}{\frac{\left[\left(1+C S_{d}\right)^{C S}\right]-1}{C S_{d}{ }^{*}\left(1+C S_{d}\right)^{C S}}}$

Electricity bill structure varies from country to country, but, in general, its costs depend on both the CS characteristics (connection capacity) and usage, and it is made up of a fixed cost $\left(C S_{e, f}\right)$ and a variable cost $\left(C S_{e, v}\right)$ which depends on the electricity consumption. Taking average values for electricity bill, ${ }^{9}$ total electricity bill costs are calculated with Eq. (4).

$\mathrm{CSO}_{\text {Electricity bill }}=\left(\mathrm{CS}_{e, f}+\mathrm{CS}_{e, v}\right) * N_{C S}$

The metering cost related to each $\mathrm{CS}\left(C S_{M}\right)$ is sometimes included in the electricity bill, while some other times it is billed separately, as it is the communication cost for each $\mathrm{CS}\left(C S_{C}\right)$. Based on the pricing strategy of existing marketplaces, the cost of accessing the marketplace does not depend on the number of CS $\left(N_{C S}\right)$, but it is a fixed annual price, which is added to a one-time registration fee.

In all the case studies considered, the CSO role is expected to be performed by an existing company (an electric utility, a parking site operator, a retail store, a gas station owner, etc.), who outsources all the issues related to the operation of the CS to a third party, ${ }^{10}$ so the CSO does not need to contract additional staff for CS operation and, hence, staff and overhead costs can be neglected. This way, the cost of operating the CS can be included in the O\&M costs.

By considering Eqs. (1)-(4), the cost of the CSO can be calculated according to Eq. (5).

$$
\begin{aligned}
C S O \text { cost }= & \left(\frac{C S_{I}}{\frac{\left[\left(1+C S_{d}\right)^{C S_{y]-1}}\right.}{C S_{d} *\left(1+C S_{d}\right)}+C S_{y}} S_{O \& M}+C S_{e, f}+C S_{e, v}+C S_{M}+C S_{C}\right) \\
& * N_{C S}+C S O_{M P}
\end{aligned}
$$

On the other hand, CSO's income results from charging services, as well as any other sources of revenue that can be obtained $\left(C S_{O S}\right)$, such as advertising, attracting customers to other businesses, etc. The income from charging services in each CS depends on the charging price $(C P)^{11}$ and the annual number of charging events in that CS $(C)$, as shown in Eq. (6).

CSO income $=\left[\left(C P^{*} C\right)+C S_{O S}\right]^{*} N_{C S}$

As a result, the minimum average charging price that the CSO needs to request, so that costs do not exceed incomes, can be calculated by making Eq. (5) equal to Eq. (6), which results in Eq. (7).

${ }^{9}$ Each CS may have different fixed electricity bill costs as they may depend e.g. on the CS power. Likewise, variable costs depend on the amount of energy charged, which depends on the state of charge of the battery, both before and after charging. The case studies presented in Section 4 consider different values for the average amount of energy to be charged per charging event, in order to present some likely conditions.

${ }^{10}$ This kind of service is already being provided by some electric utilities and equipment manufacturers, e.g. RWE (https://www.rwe-mobility.com/web/cms/en/ $1241156 /$ products-services/emobility-services/rwe-eoperate/ (last access in June 2015)).

${ }^{11}$ As shown in Eq. (7), the minimum amount of the charging price depends on a number of factors which may vary from charging station to charging station. Local conditions, e.g. taxation, competition, etc. will also have an impact on the final price to be requested by the CSO. Therefore, a spatial differentiation of charging price is likely to happen, although it is not considered in this study, in order to keep the calculations as simple as possible. 


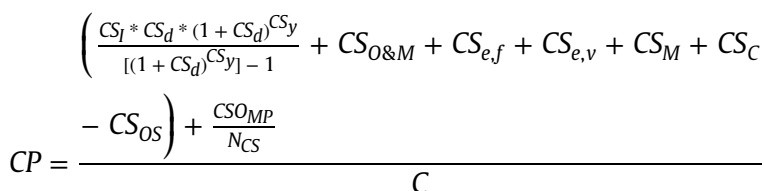

\subsubsection{Electro-mobility Service Provider (EMSP)}

The EMSP too has some fixed costs and the variable cost of each charging event. Therefore, EMSP costs can be calculated with Eq. (8).

$$
E M S P \cos t=E M S P \cos t_{f}+E M S P \cos t_{v}
$$

As the main costs for the EMSP are of fixed nature, variable costs have been assumed to be passed through directly to EV users in this study. Fixed costs include costs for accessing the marketplace, communication cost $\left(E M S P_{C}\right)$, staff and overhead cost $\left(E M S P_{S G O}\right)$ and customer management costs. The costs of accessing the marketplace, as in the case of the CSO, include a one-time registration fee and a fixed annual fee, which result in the annual fixed marketplace access cost $\left(E M S P_{M P, f}\right)$ but there is also a fee to be paid for the number of EV users in EMSP's portfolio $\left(N_{E M S P}\right)$, which results in the variable marketplace access cost $\left(E M S P_{M P, v}\right)$. Customer management costs include administration cost (which is included in staff and overhead costs) and the cost for consumer identification $\left(E M S P_{I d}\right)$, which can be done, for example, by using radio-frequency identification (RFID) cards. All these items are included in Eq. (9).

$$
\begin{aligned}
E M S P \operatorname{cost}_{f}= & \left(E M S P_{M P, v}+E M S P_{I d}\right) \\
& * N_{E M S P}+E M S P_{M P, f}+E M S P_{C}+E M S P_{S \& O}
\end{aligned}
$$

Additionally, in this analysis, fixed costs have been assumed to be recovered by means of an annual subscription fee $(S P)$ to be charged to EV users. Hence, the incomes for the EMSP are calculated with Eq. (10).

EMSP income $=S P * N_{E M S P}$

The minimum SP value that permits the EMSP to recover its costs can be calculated as shown in Eq. (11).

$S P=E M S P_{M P, v}+E M S P_{I d}+\frac{E M S P_{M P, f}+E M S P_{C}+E M S P_{S \& O}}{N_{E M S P}}$

When the EMSP has about 5000 EV users, the subscription price $(S P)$ is close to $120 \mathrm{EUR} / \mathrm{year}$, including taxes (Madina et al., 2015), which is in the upper bound of the 10-200 USD range considered in Wiederer and Philip (2010). ${ }^{12}$

\subsubsection{EV user}

EV users take many aspects into account when deciding which type, brand and model of vehicle they buy, but their decisions are usually motivated by emotions (Kley et al., 2011) and are not always rational (Abrardi and Cambini, 2015).

However, EVs offer economic advantages for vehicle users with high utilisation rates and high annual mileages, especially in urban areas, which can attract about $50 \%$ of potential EV users. Moreover, more than $50 \%$ of the driving patterns of ICE vehicle users could be satisfied by EVs, if they have a wired, private charging at low power connection available. Therefore, private charging is expected to be the preferred option by most EV users, leaving publicly accessible charging infrastructure only for sporadic use. Yet, EV users need a public charging infrastructure to be built, in order

12 Based on 1 EUR=1.3257 USD (2010) https://www.ecb.europa.eu/stats/ex change/eurofxref/html/eurofxref-graph-usd.en.html (last access in June 2015). to overcome range anxiety and feel comfortable when they drive outside their regular trip profile (Kley et al., 2011; Schroeder and Traber, 2012), which is also known as convenience charging (Wiederer and Philip, 2010).

These two types of charging infrastructure use (regular daily use of private charging infrastructure and convenience charging) result in two different values for EV users, who, consequently, will value each use under different criteria.

Regular use allows EV users to benefit from the advantages of EVs over ICE vehicles. Being a lower operational cost really relevant (Wiederer and Philip, 2010), private charging must be able to provide price-competitive charging, so that the higher vehicle purchase price can be compensated, on a total cost of ownership (TCO) basis.

On the contrary, convenience charging allows EV users to increase their driving range over their typical driving profile, i.e. increase their freedom of movement. As a result, EV users will be willing to pay a bit more to obtain that extra service. Since the value is similar to the one ICE vehicle users obtain in petrol stations, the cost per kilometre should be similar to that case.

In the most general case, EV users have some fixed costs and some variable costs, which depend on vehicle usage, as shown in Eq. (12).

$E V$ user cost $=E V$ user $\operatorname{cost}_{f}+E V$ user cost $_{v}$

Fixed costs include the EV amortisation cost - which considers the EV purchase cost $\left(E V_{I}\right)$, the discount rate $\left(E V_{d}\right)$ and the EV lifetime $\left(E V_{y}\right)$ - the EMSP subscription fee $(S P)$ and, in the case of private home charging scenario, the costs related to infrastructure: annual CS O\&M costs ( $\left.C S_{O \& M}\right)$ and CS amortisation cost, which can be calculated as in the case of the CSO, i.e. by using Eq. (3).

$E V$ user cost $_{f}=E V_{\text {Amortisation }}+S P+C S_{\text {Amortisation }}+C S_{O \& M}$

$E V_{\text {Amortisation }}=\frac{E V_{I}}{\frac{\left[\left(1+E V_{d}\right)^{E V_{y_{1}}-1}\right.}{E V_{d} *\left(1+E V_{d}\right)^{E V_{y}}}}$

Variable costs include annual EV O\&M cost - which is calculated by using the O\&M cost per kilometre $\left(E V_{O \& M}\right)$ and the annual mileage $\left(E V_{K}\right)$ - and EV charging cost $\left(E V_{C h}\right)$, as shown in Eq. (15).

$E V$ user $\operatorname{cost}_{v}=\left(E V_{O \& M} * E V_{K}\right)+E V_{C h}$

Therefore, total costs for an EV user can be calculated by using Eq. (16).

$$
\begin{aligned}
\text { EV user cost }= & \frac{E V_{I}}{\frac{\left[\left(1+E V_{d}\right)^{E V_{y]}-1}\right.}{E V_{d}^{*}\left(1+E V_{d}\right)^{E V_{y}}}}+S P+\frac{C S_{I}}{\frac{\left[\left(1+C S_{d}\right)^{\left.C S_{y}\right]-1}\right.}{C S_{d} *\left(1+C S_{d}\right)^{C S_{y}}}}+C S_{O \& M} \\
& +\left(E V_{O} \& M^{*} E V_{K}\right)+E V_{C h}
\end{aligned}
$$

This cost must be compared against the cost of ICE vehicles. In the most general case, it includes vehicle amortisation cost which considers the vehicle purchase cost $\left(I C E V_{I}\right)$, the discount rate $\left(I C E V_{d}\right)$ and the vehicle lifetime $\left(I C E V_{y}\right)$ - together with the annual O\&M costs and fuel costs. Annual O\&M costs are calculated by using the $O \& M$ cost per kilometre $\left(I C E V_{O \& M}\right)$ and the annual mileage $\left(I C E V_{K}\right)$, while fuel costs are calculated by considering the consumption per kilometre $\left(I C E V_{E f}\right)$, fuel price $(F P)$ and annual mileage, as presented in Eq. (17). ${ }^{13}$

\footnotetext{
${ }^{13}$ Eq. (17) is similar to Eq. (16), but it does include neither SP, nor costs related to the charging infrastructure. Moreover, EV charging cost is replaced by ICEV fue cost, i.e. the last term in Eq. (17).
} 


$$
\begin{aligned}
I C E V \text { user cost }= & \frac{I C E V_{I}}{\frac{\left[\left(1+I C E V_{d}\right)^{\left.I C E V_{y}\right]-1}\right.}{I C E V_{d}^{*}\left(1+I C E V_{d}\right)^{I C E V_{y}}}}+\left(I C E V_{O \& M} * I C E V_{K}\right) \\
& +\left(I C E V_{E f} * F P * I C E V_{K}\right)
\end{aligned}
$$

In order to be able to compare the costs for both alternatives, similar investment decisions $\left(E V_{d}=I C E V_{d}, E V_{y}=I C E V_{y}\right)$ and vehicle use $\left(E V_{K}=I C E V_{K}\right)$ must be considered. Under these conditions, total costs for EV users (Eq. (16)) do not exceed the costs of an equivalent ICE vehicle (Eq. (17)), when their EV charging cost is not higher than the amount calculated in Eq. (18).

$$
\begin{aligned}
E V_{C h}= & \frac{I C E V_{I}-E V_{I}}{\frac{\left[\left(1+E V_{d}\right)^{\left.E V_{y}\right]-1}\right.}{E V_{d}^{*}\left(1+E V_{d}\right)^{E V_{y}}}} \\
& +\left\{E V_{K} *\left[I C E V_{O \& M}+\left(I C E V_{E f} * F P\right)-E V_{O \& M}\right]\right\}-S P \\
& -\frac{C S_{I}}{\frac{\left[\left(1+C S_{d}\right)^{C S_{y]}-1}\right.}{C S_{d} *\left(1+C S_{d}\right)^{C S y}}}-C S_{O \& M}
\end{aligned}
$$

In scenarios for convenience charging (traffic hotspot and highway charging), the cost per kilometre is compared, so fixed costs, including investment decisions, are not considered. ${ }^{14}$ As a result, for each charging event (i), Eq. (18) results in Eq. (19).

$E V_{C h, i}=\left\{E V_{K, i} *\left[I C E V_{O \& M}+\left(I C E V_{E f} * F P\right)-E V_{O \& M}\right]\right\}$

The amount of kilometres that EV users drive as a result of each charging event depends on the amount of energy charged per event $\left(E_{i}\right)$ and the driving efficiency $\left(E V_{E f}\right)$, as Eq. (20) shows.

$E V_{K, i}=\frac{E_{i}}{E V_{E f}}$

On the other hand, EV users are final users, so they must pay the value added tax (VAT) and, hence, $E V_{c h}$ is higher than $C P$, as presented in Eq. (21).

$E V_{C h, i}=C P^{*}(1+V A T)$

As a result, Eq. (19) becomes Eq. (22).

$C P *(1+V A T)=\left\{\frac{E_{i}}{E V_{E f}} *\left[I C E V_{O \& M}+\left(I C E V_{E f} * F P\right)-E V_{O \& M}\right]\right\}$

By comparing Eqs. (7) and (22), an operator of CS for convenience charging can obtain benefits and still offer competitive prices to EV users if the CS is used at least $C$ times per year, as calculated in Eq. (23).

$$
\begin{aligned}
& \left(\frac{C S_{I} * C S_{d} *\left(1+C S_{d}\right)}{\left[\left(1+C S_{d}\right)^{\left.C S_{y}\right]-1}\right.}+C S_{O \& M}+C S_{e, f}+C S_{e, v}+C S_{M}+C S_{C}\right. \\
& C=\frac{\left.-C S_{O S}\right)+\frac{C S O_{M P}}{N_{C S}}}{\frac{E_{i}}{E V_{E f} *(1+V A T)} *\left[I C E V_{O \& M}+\left(I C E V_{E f} * F P\right)-E V_{O \& M}\right]}
\end{aligned}
$$

\section{Case studies}

Although private home charging is expected to be the preferred option for EV charging, other charging alternatives are also required by EV users in order to overcome range anxiety. Therefore, this paper presents an assessment of the economic performance of

\footnotetext{
${ }^{14} \mathrm{EV}, \mathrm{ICEV}$ and CS investment amortisation are thus removed, as well as subscription price and CS O\&M.
}

different EV charging alternatives, both for final users and for the CSO.

Sections 4.1-4.3 present the case studies for the three charging scenarios defined in Section 2. As discussed in Schroeder and Traber (2012), cost data for EV charging infrastructure is difficult to find in literature, so other data sources are needed. Most of the assumptions regarding equipment characteristics, capital expenditures and operational expenditures are based on the reports by the German National Platform for Electric Mobility (NPE, 2010; NPE, 2014). Many other data stem from the work in the EU FP7 project Green eMotion (Madina et al., 2015).

\subsection{Traffic hotspot charging}

In this scenario, EV charging is made in a publicly accessible CS, located on private property and in a much-frequented place. A typical example of a traffic hotspot is a parking site with a high demand for parking, because it is located either in the city centre or close to any kind of point of interest (museum, cinema, theatre, shopping centre, etc.). EV users are expected to use an existing direct payment system to pay both for the time they stayed parked and for charging their EV. Therefore, the parking site operator performs, at the same time, the CSO role (because it installs the charging infrastructure) and the EMSP role (because it has the contractual relationship with the EV user, which, in this case, is just a one-time payment for using the service). Consequently, there is no roaming and, hence, no need to use the marketplace $\left(\mathrm{CSO}_{M P}=0\right)$.

As EV users are expected to stay parked for some time, charging must have finished by the time they come back, but it does not need to be made very fast, so a medium-power AC charging $(22 \mathrm{~kW})$ is considered here. In order to be able to use the data in NPE (2014), the CS is assumed to have two outlets, each of which can provide $22 \mathrm{~kW}$. The investment cost of this equipment $\left(C S_{I}\right)$ is 10,500 EUR, operation and maintenance cost $\left(C S_{O \xi M}\right)$ is 1150 EUR, metering and billing cost $\left(C S_{M}\right) 375$ EUR and communications cost $\left(C S_{C}\right) 200$ EUR. Expected lifetime $\left(C S_{y}\right)$ is 7.5 years ${ }^{15}$ and discount rate $\left(C S_{d}\right) 7 \%$, which is in line with existing literature.

On the other hand, EV users are expected to drive to traffic hotspots for different reasons (shopping, leisure...), but not for charging the EV as the main goal. Therefore, although a full-charge of the EV battery requires $20 \mathrm{kWh}$ (Markkula et al., 2013; Schroeder and Traber, 2012), the average charging event demand $\left(E_{i}\right)$ is expected to be lower. In this analysis, $10 \mathrm{kWh}$ has been assumed, which, at rated power, can be charged in $27 \mathrm{~min}$.

EV efficiency $\left(E V_{E f}\right)$ depends on the $\mathrm{EV}$ itself and on the driving behaviour, ${ }^{16}$ which explains the wide spread of values in scientific literature $(0.150 \mathrm{kWh} / \mathrm{km}$ (Schroeder and Traber, 2012) and $0.200 \mathrm{kWh} / \mathrm{km}$ (Markkula et al., 2013)). For this case study, $0.150 \mathrm{kWh} / \mathrm{km}$ has been considered.

Operation and maintenance costs are $0.034 \mathrm{EUR} / \mathrm{km}\left(I C E V_{O \&} M\right.$, p) and $0.037 \mathrm{EUR} / \mathrm{km}\left(I_{C E V_{O \& M, d}}\right)$ for petrol- and diesel-powered cars, respectively, ${ }^{17}$ while they are $\left(E V_{O \& M}\right) 0.012 \mathrm{EUR} / \mathrm{km}$ for EVs. ${ }^{18}$ Fuel consumptions per kilometre are $0.056 \mathrm{l} / \mathrm{km}\left(I_{C E V_{E f, p}}\right)$

\footnotetext{
15 This figure is slightly lower than the ones considered in existing literature: 8 years (Markkula et al., 2013) and 10-15 years (Schroeder and Traber, 2012; Wiederer and Philip, 2010).

${ }^{16}$ See, for example, http://avt.inl.gov/pdf/fsev/fact2013nissanleaf.pdf (last access in June 2015).

17 Based on https://www.theaa.com/motoring_advice/running_costs/ (last access in June 2015), and 1 EUR $=0.80612$ GBP (2014) https://www.ecb.europa.eu/ stats/exchange/eurofxref/html/eurofxref-graph-gbp.en.html (last access in June 2015).

${ }^{18}$ http://www.olino.org/us/articles/2009/02/17/costs-of-the-electric-car (last access in June 2015).
} 
Table 1

Country data for the traffic hotspot charging case study.

\begin{tabular}{lccc}
\hline & Spain & Germany & The Netherlands \\
\hline 2014 Petrol price $\left(F P_{p}\right)$, EUR/l & 1.383 & 1.540 & 1.699 \\
2014 Diesel price $\left(F P_{d}\right)$, EUR/l & 1.303 & 1.359 & 1.406 \\
Fixed part of electricity bill, EUR/ & 3808.27 & 103.20 & 1356.45 \\
year & & & \\
Price in period 1, EUR/kWh & 0.12238 & 0.25 & 0.1874 \\
Price in period 2, EUR/kWh & 0.09622 & 0.25 & 0.1874 \\
Price in period 3, EUR/kWh & 0.06592 & 0.25 & 0.1874 \\
VAT & $21 \%$ & $19 \%$ & $21 \%$ \\
\hline
\end{tabular}

and $0.049 \mathrm{l} / \mathrm{km}\left(I C E V_{E f, d}\right)$ for petrol- and diesel-powered cars, respectively. ${ }^{19}$

All these items are expected to be quite constant in different countries, but there are some other more country-specific. In this paper, the data for Spain, Germany and the Netherlands are used (MINETUR (2015) presents the average annual fuel prices for 2014 and EC (2015) the VAT applicable in each Member State). Moreover, the electricity bill structure is also different from country to country; for example, supply points with a contracted power of more than $15 \mathrm{~kW}$ have a three-period grid access fee in Spain, but not in Germany and the Netherlands (a detailed description of how the electricity bill is calculated can be found in Madina et al. (2015)). Table 1 presents the data to be considered.

Based on the CS usage analysis in Green eMotion (Corchero et al., 2014), it is assumed that $25 \%$ of charges are made in the most expensive period 1 (from 11:00 to 15:00 in European Summer Time and from 18:00 to $22: 00$ the rest of the year), $15 \%$ in the cheapest period 3 (from midnight to 8:00 throughout the year) and the remaining $60 \%$ in period 2 (which covers the rest of the time).

By using these data in Eq. (23), it can be calculated the minimum CS usage which allows the CSO to recover its costs and still offer an EV charging price which results in the same cost per kilometre for EV users as for diesel-powered vehicle users (which, with these data, is lower than for petrol-powered vehicle users). This minimum CS usage is between 3.83 times (Germany) and 5.24 times (Spain) per day on average.

However, the CSO can also obtain additional incomes from e.g. advertising in the CS. In that case, the minimum required CS usage so that the CSO can design a profitable business model is presented in Fig. 2.

The CS has significant fixed costs and low variable costs, so the CSO wants to have it in operation for as long as possible. Therefore, a time-dependent, variable pricing strategy is envisaged. ${ }^{20}$

\subsection{Highway charging}

In the highway charging scenario, EV charging is made in a publicly accessible CS, located on private property in a highway, and with fast DC charging capabilities ( $50 \mathrm{~kW}$ ). A typical example of this type of charging is an existing highway petrol station, where a fast DC charger is installed. It is assumed that EV users use roaming agreements of their EMSP and of the petrol station owner (CSO) with a marketplace operator.

The data for the equipment considered in this case study can also be obtained from NPE (2014). Investment cost $\left(C S_{I}\right)$ is 27,150

\footnotetext{
${ }^{19}$ Equivalent to the $2015 \mathrm{EU}$ target on $\mathrm{CO}_{2}$ emissions: http://ec.europa.eu/cli $\mathrm{ma} /$ policies/transport/vehicles/cars/ (last access in June 2015).

${ }^{20}$ For example, in Spain, fixed costs are about EUR 7350 for CS amortisation, $\mathrm{O} \& \mathrm{M}$ and fixed part of the electricity bill, while variable costs are about $10 \mathrm{ct} / \mathrm{kWh}$ on average. During the EV charging process, the price may be set to make charging price competitive against ICE vehicle mileage cost (about $50 \mathrm{ct} / \mathrm{kWh}$, or $18 \mathrm{ct} / \mathrm{min}$.). After the charging process finishes, the EV user may still be asked to pay an amount to the CSO to compensate for not making the CS available to other users (e.g. $3 \mathrm{ct} / \mathrm{min}$.).
}

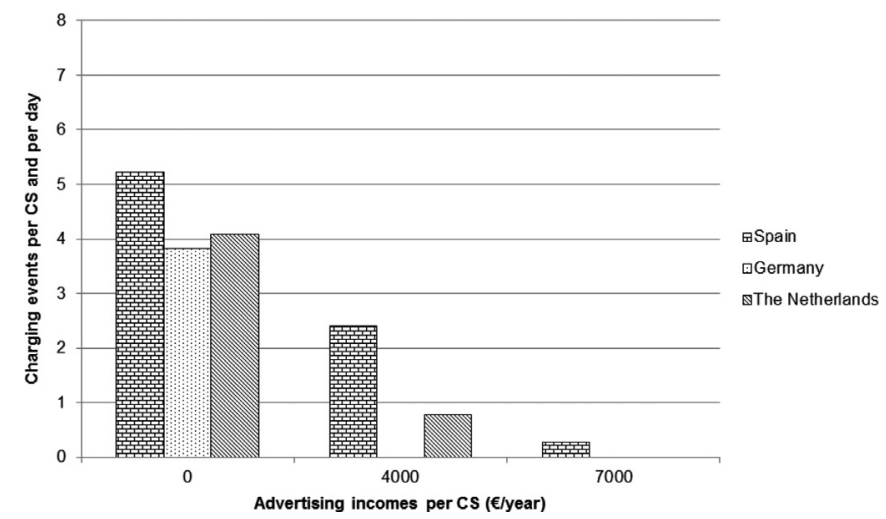

Fig. 2. Required CS usage per country in the traffic hotspot charging case study.

EUR, O\&M cost 2500 EUR $\left(C S_{O \& M}\right)$, metering and billing cost $\left(C S_{M}\right)$ 375 EUR, cost of communications $\left(C S_{C}\right) 200$ EUR and the expected lifetime $\left(C S_{y}\right) 7.5$ years. The same discount rate $\left(C S_{d}\right)$, operation and maintenance costs $\left(I C E V_{O \& M, p}\right.$ and $\left.I C E V_{O \& M, d}\right)$ and charging event distribution per period as in the traffic hotspot case are considered. Again, diesel-powered vehicles are the benchmark for comparing with EVs, since they offer lower costs per kilometre than petrol-powered ones.

On the contrary to the case of traffic hotspot charging, EV users are expected to charge their battery as much as possible, so the average charging event demand $\left(E_{i}\right)$ is expected to be $20 \mathrm{kWh}$. Likewise, highway driving usually requires more energy than driving in the city, so EV efficiency $\left(E V_{E f}\right)$ is considered to be $0.200 \mathrm{kWh} / \mathrm{km}$ and fuel consumptions by ICE vehicles are also increased by 33\%. The same data as in Table 1 are also used in this case study, except for the fixed part of the electricity bill in Spain (4325.35 EUR) and the Netherlands (1668.29 EUR) ${ }^{21}$. Due to the incipient status of the EV market, it is considered that the CSO has only one CS. The marketplace access cost for the CSO $\left(\mathrm{CSO}_{M P}\right)$ is 2000 EUR/year (Madina et al., 2015).

By using Eq. (23), the CSO can offer EV users a cost per kilometre which is competitive with diesel-powered vehicles and still make a profit, as long as the CS is used for 5.54 charging events per day in Spain, 6.01 charging events per day in Germany and 5.36 charging events per day in the Netherlands.

In this case too, the CSO can obtain additional incomes from advertising in the CS. Furthermore, due to the expected charging time $(20 \mathrm{kWh} / 50 \mathrm{~kW}=24 \mathrm{~min})$, highway charging can be a good alternative for CSOs who own a restaurant. At an average 1.50 EUR additional income from the restaurant (Madina et al., 2015), the required CS usage can be further reduced, as presented in Fig. 3.

\subsection{Private home charging}

Private home charging presents the situation where EV users buy and install a low-capacity $(3.7 \mathrm{~kW}) \mathrm{CS}$ in their homes for charging their EV. Hence, the CS is located in private property with restricted access and EV users perform the CSO role. It is assumed that the EV is supplied from a new electricity supply point and, thus, that the CS is independent from the existing home electricity installation.

Most EV users are expected to charge their EVs at home when available, so this scenario will have a strong impact on EV users' TCO and, hence, all the costs of EVs must be compared against the costs of ICE vehicles.

Some of the data to be used are the same as in the case studies described above $\left(E V_{O \varepsilon M}, I C E V_{O \& M, p}\right.$ and $I C E V_{O \varepsilon M, d}, F P_{p}$ and $F P_{d}, C S_{y}$

\footnotetext{
${ }^{21}$ See Madina et al. (2015) for details.
} 


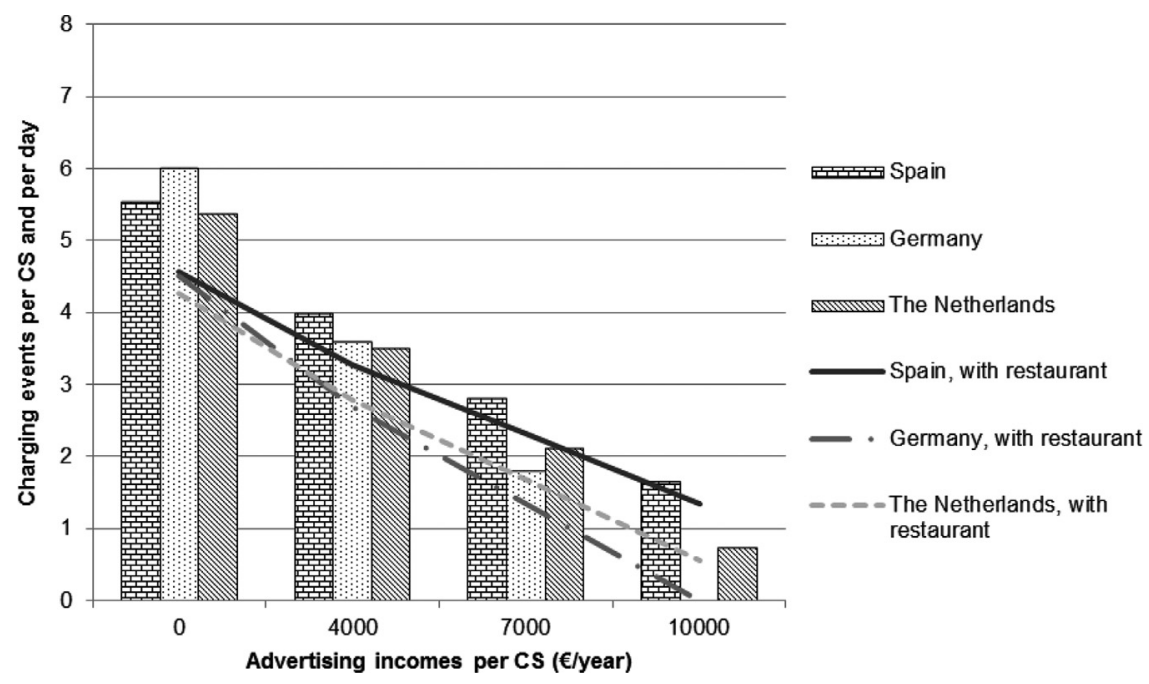

Fig. 3. Required CS usage per country in the highway charging case study.

and $\left.C S_{d}\right)$. Regarding efficiencies $\left(E V_{E f}, I C E V_{E f, p}, I C E V_{E f, d}\right)$, the driving behaviour is not expected to request as much energy as in the highway, but to be close to average driving patterns, as in the traffic hotspot case, so the same efficiencies as in Section 4.1 have been taken into account.

On the contrary, the distribution of charging events is assumed to be $100 \%$ during the night period, so that EV users can benefit from lower electricity prices. $^{22}$

NPE (2014) does not include cost estimates for private charging CS. The closest CS presented there is the public street light wall box charger, whose investment cost is 2500 EUR and O\&M is 1175 EUR. Some previous estimates consider investments between 500 EUR (Schroeder and Traber, 2012) and 1885 EUR $^{23}$ (Wiederer and Philip, 2010), and there is equipment in the market at 735 EUR, without installation. ${ }^{24}$ To be on the safe side, investment cost $\left(C S_{i}\right)$ has been assumed to be 1500 EUR and O\&M costs $\left(C S_{\text {OGM }}\right) 50$ EUR (Schroeder and Traber, 2012) per year, with no additional metering and billing $\left(C S_{M}\right)$ or communications costs $\left(C S_{C}\right)$, because the CS is for private use.

Regarding vehicle purchase prices, Table 2 presents the values considered for the different countries (Madina et al., 2015). Vehicle lifetime is assumed to be 12 years, with a $7 \%$ discount rate. ${ }^{25}$

There is wide spread in estimations of annual mileages in literature, which vary from about $15,000 \mathrm{~km} /$ year (Schroeder and Traber, 2012) to 36,500 km/year (Markkula et al., 2013). In 2008, passenger transport resulted in about $13,138 \mathrm{~km} /$ person, $72 \%$ of which was in passenger cars, ${ }^{26}$ with occupancy rates in the range of 1.5 people per car, ${ }^{27}$ i.e. about $14,200 \mathrm{~km} /$ year per vehicle. As EVs drive about $40 \%$ more than ICE vehicles, ${ }^{28}$ the annual mileage $\left(E V_{k}\right)$ has been assumed to be $20,000 \mathrm{~km} /$ year.

\footnotetext{
${ }^{22}$ The process to calculate the electricity bill is described in Madina et al. (2015).

${ }^{23}$ Based on 1 EUR=1.3257 USD (2010), https://www.ecb.europa.eu/stats/ex change/eurofxref/html/eurofxref-graph-usd.en.html (last access in June 2015).

${ }^{24}$ Such as the equipment in: http://www.efimarket.com/punto-recargamodo3-new-wallbox (last access in June 2015), which is compatible with the International Electrotechnical Commission (IEC) 62196 and 61851 standards, and provides $3.7 \mathrm{~kW}$ charging in Mode 3 .

${ }^{25}$ The process to obtain the data in Table 2 is described in Madina et al. (2015)

26 http://ec.europa.eu/transport/facts-fundings/statistics/doc/2010/pb2010_3_ transport.pdf (last access in June 2015).

27 http://www.eea.europa.eu/data-and-maps/indicators/occupancy-rates-ofpassenger-vehicles/occupancy-rates-of-passenger-vehicles-1 (last access in June 2015)

28 http://newsroom.nissan-europe.com/EU/en-gb/Media/Media.aspx?med iaid $=128267$ (last access in June 2015).
}

Table 2

Country data for the private home charging case study.

\begin{tabular}{lccc}
\hline & Spain & Germany & The Netherlands \\
\hline$I C E V_{i, p}$ (EUR) & 12,000 & 13,150 & 16,150 \\
$I C E V_{i, d}$ (EUR) & 13,800 & 15,550 & 18,550 \\
$E V_{i}$ (EUR) & 16,500 & 24,150 & 27,150 \\
\hline
\end{tabular}

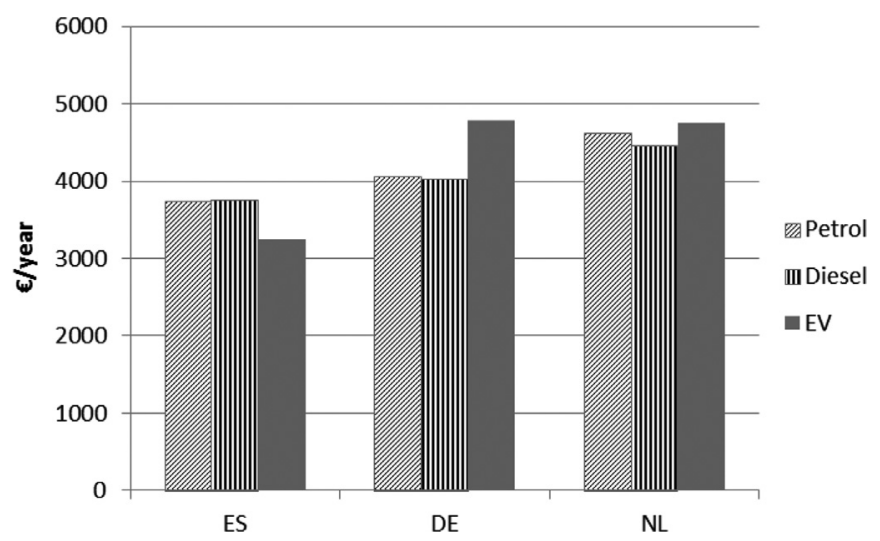

Fig. 4. TCO comparison per country in the private home charging case study.

Under these conditions, the TCOs for different types of vehicle are presented in Fig. 4.

\subsection{Discussion}

In this analysis, charging prices in traffic hotspots and in highways are established so that the cost per kilometre for EV users is comparable to drivers of ICE vehicles. Therefore, the higher EV purchase cost must be compensated through private home charging, so that EV users have a competitive TCO against ICE vehicles. The number of kilometres that EV users must drive by using private home charging is about $14,550 \mathrm{~km} / \mathrm{year}$ in Spain, $36,175 \mathrm{~km} /$ year in Germany and $24,875 \mathrm{~km} /$ year in the Netherlands. The lower mileage in Spain is mostly due to the subsidies to vehicle purchase (6500 EUR), as about $23,825 \mathrm{~km} /$ year would be required in Spain if there were no subsidies for EV purchase.

On the other hand, battery costs have declined between $8 \%$ and $14 \%$ in recent years (Nykvist and Nilsson, 2015). With an additional $8 \%$ decline over the next 3 years, EVs would become the lowest TCO option in Spain and in the Netherlands, even without any type 
of public support, as long as private home charging is used to drive $20,000 \mathrm{~km} / \mathrm{year}$. On the contrary, the conditions in Germany require both a steeper decline (in the upper range of $14 \%$ ) and a longer period (5.25 years) to make EVs competitive against ICE vehicles.

Although private home charging is expected to be the preferred scenario for EV users, EV charging in publicly accessible infrastructure is also required for the widespread adoption of electromobility. However, due to their likely low rate of use, it is difficult that these CS will pay off on a pay-per-use tariff, so their number should be kept to a minimum (Schroeder and Traber, 2012). It is expected that $85 \%$ of the required charging infrastructure will be for private charging (either at home or at work), $10 \%$ will be publicly accessible CS in private property (9\% AC, $1 \%$ DC) and the remaining $5 \%$ will be publicly accessible CS in public property (NPE 2014).

In the case of the traffic hotspot charging, the minimum CS usage so that the CSO can offer competitive prices for EV users (so that their cost per kilometre is comparable to the cost of ICE vehicles) and still make a profit is between 3.85 (Germany) and 5.25 (Spain) times per day on average (1400-1900 charging events per year). An important lesson for CSOs is that, considering that this scenario would account for about $9 \%$ of the charging events, the required CS usage will be reached when the traffic hotspot serves between 45 EVs in Germany and 61 EVs in Spain. A good way to increase CSO's income (and, thus, reduce the required CS usage) is to use the CS for advertising purposes: if the CSO can obtain additional incomes of about 3675 EUR (Germany), 4930 EUR (The Netherlands) or 7380 EUR (Spain) in each CS, those incomes would pay for all the fixed costs.

Due to the higher investment and operational costs of highway fast charging, together with the worse EV efficiency in highways, this kind of CS must be used more frequently (by increasing either the average kilowatt-hours per charge or the average number of charges per day $^{29}$ ) to find a profitable business case for the CSO. Therefore, the CSO must explore further sources of income, such as advertising or using the fast CS to attract EV users to an existing shop or restaurant. If about 4000 EUR can be obtained from advertising, attracting 3.5 EV users (4 in Spain, again for the bigger impact of the fixed part of the electricity bill) per day to the restaurant can create a profitable business for the CSO. Even in that case, the likely low usage of the CS (just $1 \%$ of EV charges are expected to be fast charges) require a customer base of about 600$650 \mathrm{EV}$ users using fast charging. Without additional incomes, the required $\mathrm{EV}$ user base rises to $900-1000$.

\section{Conclusion and policy implications}

Electro-mobility is a complex ecosystem, where different actors create a network of interactions and collaborate to create a positive business case. This paper has presented the results of the economic assessment of the impact that three electric vehicle (EV) charging scenarios have in different electro-mobility actors. In each of them, the required charging station (CS) usage is calculated, so that the charging service operator (CSO) covers its costs while, at the same time, the price for EV charging still allows EV users to have a cost comparable to internal combustion engine (ICE) vehicles.

Consequently, according to this analysis, it can be stated that

\footnotetext{
${ }^{29}$ The average charging event must demand twice as much energy as in the traffic hotspot case to have a comparable average use per day in Spain, and three times as much energy in Germany and in the Netherlands. With the same average energy demand per day, the required number of charges per day rises up to 11-12 charges per day in the three countries.
}

users who have access to private home charging are expected to be the early adopters of EVs, as their total cost of ownership (TCO) can be lower than the cost of ICE vehicles, as long as they drive high annual mileages, charge their EVs at lower prices overnight and benefit from subsidies for EV purchase. Once there are some tens of EVs in an area, there might be enough demand for charging in publicly accessible CS, so traffic hotspot charging can become profitable. In order for highway fast charging to become profitable, the number of potential users of each CS should rise to some hundreds or even thousands, so it is not likely to be profitable in the short-term.

Regulatory authorities should contribute to speed up the deployment of electro-mobility by improving the economics for both CSOs and EV users, although their task is very difficult in brand new environments such as electro-mobility, both because of the lack of experience and because costs and benefits are unknown, even to stakeholders. The analysis presented in this paper is aimed at guiding them through the process of setting the grounds for EV charging infrastructure deployment, but regulators may have some additional requirements that fall out of the scope of this analysis.

Although private charging is expected to be the preferred option by most EV users, a public charging infrastructure will still be needed, so that EV users can overcome range anxiety and feel comfortable when they drive outside their regular trip profile. Therefore, electro-mobility promotion measures must consider both private and convenience charging, which have different support requirements.

One important aspect to be taken into account by regulators is the way to structure the electricity bill. For example, the main difference in the traffic hotspot case between Spain and Germany stems from the higher share of the fixed part of the electricity bill in Spain. The same effect seems to appear publicly accessible CS for street side parking (Madina et al., 2015), but more detailed analyses are required. A tool for regulatory bodies to promote electro-mobility can be to establish specific tariffs for CS operators, where the variable part has more weight than the fixed part of the bill. $^{30}$ In the early stages of deployment, when CS usage is expected to be modest, high fixed costs in electricity tariffs can hinder the creation of sustainable business models, so reduced fixed prices are helpful. On the contrary, a slight increase in the energy-based component of the tariff would still allow a lower cost per kilometre for EVs when compared against ICE vehicles.

With regard to EV users, the access to cheaper electricity for overnight charging is also very helpful to improve the total cost of ownership (TCO). In the case of Spain, the use of a single-price tariff (at $0.124107 \mathrm{EUR} / \mathrm{kWh}$, instead of $0.044146 \mathrm{EUR} / \mathrm{kWh}$ (BOE, 2014)) for private home charging would increase the TCO in about $200 \mathrm{EUR} / \mathrm{year}$, and the required annual mileage would also rise in about $2200 \mathrm{~km} /$ year. Where price difference between the singleprice tariff and the reduced (night) tariff is not so high, as in the Netherlands, ${ }^{31}$ the effect on the TCO is lower (about 30 EUR/year), as well as on the required annual mileage (about $500 \mathrm{~km} /$ year).

Instead of subsidies for EV purchase, governments and regulatory bodies could promote electro-mobility by offering tax rebates (Wiederer and Philip, 2010) e.g. in car vehicle tax, in

\footnotetext{
${ }^{30}$ In August 2013, the T\&D tariff structure was changed in Spain (Orden IET) $1491 / 2013$ ), so that the power term was increased (233\% on average for the tariffs considered for traffic hotspots and highway chargers) and the energy term reduced (divided by 4 on average for the same tariffs). With the old tariff structure, the traffic hotspot would have needed about 4.12 charges per day (compared to the 5.24 charges per day required under present tariff structure) and the highway charging 5.16 (compared to 5.53 charges required now).

31 http://www.nuon.nl/energie/standaard-energie/prijzen.jsp (last access in June 2015)
} 
electricity tax or VAT for electricity consumed in private home charging. When taxes are removed from the electricity bill for private home EV charging, the required annual mileage for EV users to have a TCO comparable with ICE vehicles is reduced to about $13,000 \mathrm{~km} /$ year ( $10 \%$ reduction), $30,000 \mathrm{~km} /$ year ( $17 \%$ reduction) and 21,000 km/year (16\% reduction) for Spain, Germany and the Netherlands respectively. Moreover, tax rebates may also offer advantages over direct subsidies for the government. In the case of Spain, an EV user with an annual mileage of $14,550 \mathrm{~km} /$ year (breakeven point without tax rebates), the electricity bill tax rebate would be about 147 EUR/year, but its impact on EV user's TCO would be equivalent to a direct EV purchase subsidy of 5400 EUR, i.e. 1100 EUR below the required subsidy without tax rebates.

\section{Acknowledgements}

The authors would like to thank the industrial partners who contributed to the business models work performed in Green eMotion project, which is the basis for this paper. In particular, it is specially acknowledgeable the overall strategic support by Heike Barlag and Thomas Gereke from Siemens, much appreciated the utility view by Sven Jundel (RWE) and Giovanni Coppola (Enel) and very valuable the assistance by Holger Braess and Michael Hajesch (BMW) and Sara Tij (Nissan), as well as their enthusiastic contributions to the fruitful discussions and several workshops held during the four years of the project.

The research leading to these results has received funding from the European Union Seventh Framework Programme FP7/20072013 under Grant agreement no. 265499.

\section{References}

Abrardi, L., Cambini, C., 2015. Tariff regulation with energy efficiency goals. Energy Econ. 49, 122-131.

BOE, 2014. Resolución de 31 de enero de 2014, de la Dirección General de Política Energética y Minas, por la que se revisa el coste de producción de energía eléctrica y los precios voluntarios para el pequeño consumidor. Ministerio de Industria, Energía y Turismo. BOE-A-2014-1053.

Bohnsack, R., Pinkse, J., Kolk, A., 2014. Business models for sustainable technologies: exploring business model evolution in the case of electric vehicles. Res. Policy 43, 284-300.

Corchero, C., González-Villafranca, S., Sanmartí, M., 2014. European electric vehicle fleet: driving and charging data analysis. In: Proceedings of the Electric Vehicle Conference (IEVC), 2014 IEEE International. 17-19 December 2014. Florence, Italy.

European Commission (EC), 2015. VAT rates applied in the Member States of the European Union. Situation at 1st January 2015. European Commission. Taxud.c.1.

Eto, J., Stoft, S., Kito, S., 1998. DSM shareholder incentives: recent designs and economic theory. Util. Policy 7 (1), 47-62.

Eurelectric, 2010. Market models for the roll-out of electric vehicle public charging infrastructure. Eurelectric Concept Paper. September 2010.

Eurelectric, 2013. Deploying publicly accessible charging infrastructure for electric vehicles: how to organise the market? Eurelectric Concept Paper. July 2013.

German National Platform for Electric Mobility (NPE). Interim Report of the National Platform for Electric Mobility, Federal Government Joint Unit for Electric Mobility, 2010; Berlin.

German National Platform for Electric Mobility (NPE). Progress Report 2014 - Review of pre-market phase, Federal Government Joint Unit for Electric Mobility, 2014; Berlin.

Gomez, San Román, T., Momber, I., Abbad, M.R., Sánchez Miralles, A., 2011. Regulatory framework and business models for charging plug-in electric vehicles: infrastructure, agents, and commercial relationships. Energy Policy 39, 6360-6375.

Hannon, M.J., Foxon, T.J., Gale, W.F., 2013. The co-evolutionary relationship between energy service companies and the UK energy system: implications for a lowcarbon transition. Energy Policy 61, 1031-1045.

Kley, F., Lerch, C., Dallinger, D., 2011. New business models for electric cars-a holistic approach. Energy Policy 39, 3392-3403.

Madina, C., Zabala, E., Gómez, I., Barlag, H., Gereke, T., Jundel, S., Rösler, H., Usmani, O., Hajesch, M., Coppola, G., Cruz, M., O'Mahony, M., 2015. Deliverable D9.4 Part 2: envisaged EU mobility models, role of involved entities, and cost benefit analysis in the context of the European clearing house mechanism. Green eMotion project, European Union Seventh Framework Programme FP7/20072013 under Grant Agreement no. 265499.

Magretta, J., 2002. Why business models matter. Hardvard Business Review. May 2002.

Markkula, J., Rautiainen, A., Järventausta, P., 2013. The business case of electric vehicle quick charging - no more chicken or egg problem. EVS27 Symposium. November 2013. Barcelona.

Moore, J.F., 1996. The Death of Competition: Leadership \& Strategy in the Age of Business Ecosystems. Harper Business, New York, ISBN 0-88730-850-3.

Moore, J.F., 2006. Business ecosystems and the view from the firm. Antitrust Bull. 51 (1), 31-75.

MINETUR, 2015. Precios de carburantes y combustibles. Comparación 2014-2013. Ministerio de Industria, Energía y Turismo, Madrid.

Nykvist, B., Nilsson, M., 2015. Rapidly falling costs of battery packs for electric vehicles. Nat. Clim. Chang. 5, 329-332.

Osterwalder, A., Pigneur, Y., 2010. Business Model Generation: A Handbook for Visionaries, Game Changers, and Challengers. John Wiley \& Sons, Chichester, United Kingdom, ISBN 978-0-470-87641-1.

Schroeder, A., Traber, T., 2012. The economics of fast charging infrastructure for electric vehicles. Energy Policy 43, 136-144.

Stoft, S., Gilbert, R., 1994. A review and analysis of electric utility conservation incentives. Yale J. Regul. 11 (1), 1-42.

Wiederer, A., Philip, R., 2010. Policy options for electric vehicle charging infrastructure in C40 cities. Transportation Clinton Climate Initiative. 